14

in the next 12 months

- The government's handling of NHS dentistry is having a devastating impact on morale. Seventy-two percent state the lack of clarity over the government's controversial imposed activity targets is having a high impact on their morale. Seventy percent say the same given uncertainty over the direction of pledged reforms to the service

- Nearly $2 / 3$ of practices (62\%) estimate they are continuing to operate under $70 \%$ of their pre-COVID capacity.

The BDA and Healthwatch both issued a joint message to Chancellor Rishi Sunak ahead of the budget to guarantee funding for the rebuild and recovery of services. At this time, not a penny of the government's multi-billion-pound catch-up programme has been allocated to primary care dentistry. Over 37 million NHS appointments have been lost since lockdown in England alone, over 11 million for children. Tooth decay has been long established as the number one reason for hospital admissions among young children.

While the government has pledged reform of NHS dentistry by April 2022, the BDA has consistently warned that steps must be taken to stem the flow of talent from the workforce, and to provide the necessary resources to underpin any new system.

BDA Chair Eddie Crouch said: 'It is tragic that so many million children are missing out on dental care. The government has a duty to ensure this does not become the new normal.
'For the sake of families across England we need to see real ambition from Ministers. Patients are still struggling to secure appointments, and a frustrated workforce is looking for the exit.

'The Government keeps saying NHS dentistry is a top priority, but not a penny of investment has been offered.

'These problems are being felt in every community, and require deeds, not words.'

\section{Reference}

1. Healthwatch England. What people have told us about NHS dentistry: A review of our evidence - April to September 2021. December 2021. Available at: https://www.healthwatch.co.uk/sites/healthwatch. co.uk/files/reports-library/20211014_HWE\%20 Dentistry\%20Update\%20Dec\%202021.pdf (accessed December 2021).

\title{
'A challenge we can no longer afford to ignore'
}

\author{
By Peter Aldous, Conservative Party MP for the Waveney constituency, Suffolk
}

Access to NHS dental services is a problem that has been brewing for a long time. Now it has been exacerbated by COVID, there are parts of the country, particularly rural and coastal areas, where there are 'dental deserts'. Worryingly, long-standing systemic problems - coupled with the added challenges posed by the pandemic mean that we are now facing an exodus of dentists from the NHS. As the service faces a double whammy of increased demand and reduced supply, NHS dentistry is at a tipping point and it is clear that if we don't take urgent action, the damage will be hard to undo.

As the Health and Care Bill makes its way through Parliament, I worked with the BDA to highlight the need for urgent action to address the crisis we see in the sector. An amendment I tabled to the Bill would have required the Secretary of State to report annually on the levels of access to NHS dentistry and the action being taken to improve them. The fact that 36 other MPs representing four parties and every corner of England joined me to co-sponsor New Clause 18 speaks volumes about the scale of the problem which is now felt in every community.
For months, the lack of access to NHS dentistry has been the number one issue about which constituents contact me, but the crisis is not confined to East Anglia. I think Chair of Healthwatch England Sir Robert Francis QC summed it up well when he recently said 'every part of the country is facing a dental care crisis, with NHS dentistry at risk of vanishing into the void'. This really is a challenge we can no longer afford to ignore.

Introducing the amendment, I argued that we need to increase funding for NHS dentistry, to both tackle the backlog created by the pandemic and to meet the growing oral health needs of an ageing population. In real terms, net government spend on general dental practice in England has been cut by about a third in the last decade. As the reforms set out in the Health and Care Bill are implemented, it is vital that dental funding streams across primary and secondary care are protected against further cuts.

I also called for action to improve the recruitment and retention of dental professionals, including crucially the badly needed reform of the dental contract. Current arrangements were widely considered unfit for purpose before COVID struck, and they are completely incompatible with providing safe and sustainable services for patients in the context of a pandemic. It is crucial that the new contract, which has been developed for over a decade, is rolled out without further delays and a new system is put in place which breaks with the flawed UDAs, prioritises prevention, and ensures that NHS dentistry is available to all those who need it

Finally, I argued that dentists must have a voice in Integrated Care Boards and Partnerships, with mandated presence in the new structures. Dental services are a crucial and integral part of the NHS and they cannot be an afterthought in the upcoming reforms.

While New Clause 18 was not passed, the Ministers have agreed to meet with me to discuss how the issues above can be addressed, and I will continue to raise this crucial subject in Parliament.

People are pulling out their own teeth, children are having whole mouth replacements and early signs of cancer are going undetected. We need to act now to put in place an NHS dentistry system fit for the twenty-first century, instead of reverting to the nineteenth century. 